\title{
SINESTESIAS DO ESPAÇO NA EDUCAÇÃO INFANTIL
}

\author{
Ewelyn Mayara Vieira Richieri ${ }^{1}$
}

Como é o espaço onde se desenvolve a educação de crianças pequenas? Essa foi a questão que norteou a minha pesquisa/ação como estagiária em uma turma de berçário no CECI - Centro de Convivência Infantil, da UNICAMP, sob a perspectiva experiencial da criança no espaço, suas experiências íntimas com o mundo, os desbravamentos para ocupar novos territórios, brinquedos ou outros objetos...

Quarenta semanas é o tempo estimado de uma gestação humana normal, sem intercorrências. Durante sua formação, de embrião a feto, de feto a bebê, o ser humano passa por muitas transformações dentro do mesmo espaço, o útero de sua mãe, para depois do nascimento, mudar-se para um novo ambiente. Deixa um lugar com sons agradáveis, escuro, úmido e quente de repente, para habitar um mundo claro, barulhento e frio. O bebê passa a experimentar o novo mundo que não mais lhe priva de esticar suas pernas e braços, e descobre assim sensação da liberdade.

Sem o cordão umbilical que lhe garantia o sustento, o bebê sente a dor da fome. Através do reconhecimento da fome, alguém lhe oferece alimento, o que faz seu estomago dilatar enquanto é preenchido pelo leite, e o bebê tem a sensação de "estar cheio". Logo o leite é digerido, e o estômago se contrai, e a sensação de "vazio", a fome, faz o bebê chorar novamente. Assim o humano tem os primeiros contatos com as percepções de cheio e vazio, e futuramente irá relacioná-las com a ocupação do espaço.

No início da vida, principalmente nos países ocidentais, o bebê passa muito tempo na posição horizontal, deitado, seja no carrinho ou no berço. Depois de ser alimentado, é colocado apoiado no ombro de um adulto, que lhe dá palmadinhas para que ele arrote, e assim o bebê experimenta a posição vertical. No primeiro mês de vida o bebê pode fixar o olhar em um objeto que esteja bem próximo de si; com dois meses ele adquire a fixação binocular, que consiste na junção das imagens captadas pelos dois olhos numa única imagem. Esses fatores contribuem, futuramente, para a percepção de distância e localização de um objeto no espaço.

Quando o bebê começa a frequentar o berçário, possui entre quatro e seis meses de vida. Tanto o ambiente quanto as pessoas que o frequentam são desconhecidos para ele. O berçário representa um espaço novo, a ser explorado, desvendado, até tornar-se um lugar, dotado de valores e representações para o bebê. É experimentando o novo ambiente que ele aprenderá a engatinhar e a andar, entre outras coisas. Segundo Yi-Fu-Tuan (1930), "O lugar é segurança e o espaço é liberdade".

'Espaço' é mais abstrato que 'lugar'. O que começa como espaço indiferenciado transforma-se em lugar à medida que o conhecemos melhor e o dotamos de valor. (Tuan, 1930, p. 6).

O autor considera ainda que o primeiro ambiente que a criança descobre são seus pais, ou, na falta desses, seus cuidadores, e é em função da presença ou ausência do adulto conhecido que o bebê desenvolverá suas habilidades motoras. Com poucas semanas de vida o bebê atentase à presença de outras pessoas e começa a adquirir o sentido de distância e direção através da necessidade de julgar onde possa estar o adulto.

No caso do berçário, são as professoras que conduzem esse aprendizado, estabelecendo relações de confiança e segurança entre a criança, o adulto e o espaço. Através de

\footnotetext{
${ }^{1}$ Universidade Estadual de Campinas.
} 
experimentações e explorações, investidas de sucesso, do aprendizado adquirido com os "tombos", a consequente apropriação do espaço passa a transformá-lo em lugar.

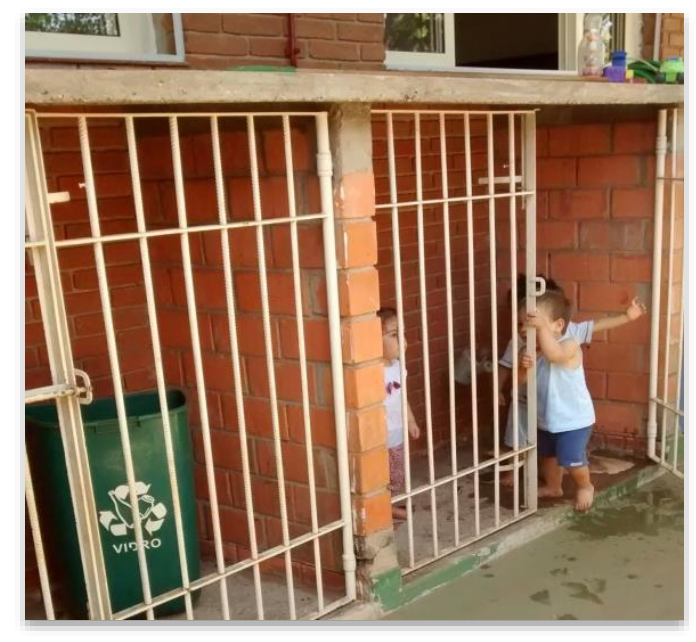

A partir da segurança e estabilidade do lugar estamos cientes da amplidão, da liberdade e da ameaça do espaço e vice-versa. (...) Se pensarmos no espaço como algo que permite movimento, então lugar é pausa; cada pausa no movimento torna possível que localização se transforme em lugar. (Ibidem, p. 6)

Durante o estágio, foi possível observar muitas relações entre as crianças e o espaço, entre as crianças e o lugar. Um bebê recém-chegado ao berçário chorava muito quando era colocado no chão junto aos demais, e se mantinha calmo quando colocado no carrinho, mesmo que permanecendo junto da turma. Quando questionei a professora sobre aquele comportamento, ela respondeu que no carrinho a criança se sentia segura, não se sentia ameaçada. Entendemos então que o carrinho representava um lugar, enquanto o restante do salão e as pessoas presentes - crianças, professoras, estagiárias, equipe de limpeza - representavam o espaço.

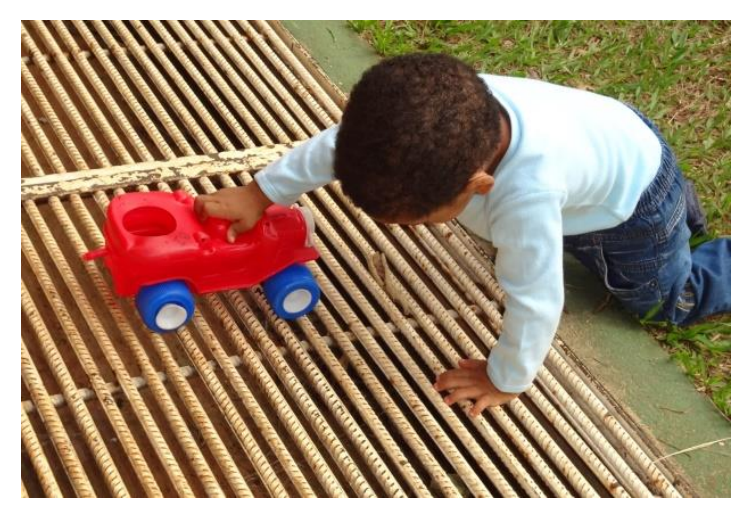

Percebe-se também na creche a apropriação do espaço como lugar quando vemos as crianças dentro das casinhas, das caixas, de um local destinado a guardar brinquedos, quando um bebê chora e um adulto o pega no colo findando o choro, ou como reconhecem e diferenciam cada ambiente do prédio quando alguém pergunta “onde está sua mochila?" e a criança se dirige ao vestiário e aponta ao objeto solicitado. 


\section{O espaço da educação infantil: que lugar é esse?}

A educação em todas as suas modalidades pode ocorrer em vários espaços, determinados, não formais e até espontâneos, de caráter informal, mas quando a educação passa a fazer parte do objeto de estudo da pedagogia o espaço é a materialidade da institucionalização do sistema educacional.

Nas experiências do estágio de educação infantil refletimos sobre o espaço destinado para a educação das crianças, os usos do espaço escolar como garantia para a criação de meninos e meninas pequenas. (AMBROGI, 2011, p. 63).

O educador deve ter consciência da ideia de representações do espaço, para não cometer o erro de dizer, por exemplo, que aquele espaço é acolhedor e promove experiências de criação, quando para uma criança pode significar um espaço ameaçador e estéril para a sua experiência criadora. Não se trata de relativizar a compreensão espacial, mas de considerar importante a relação íntima da criança com o seu espaço.

um mesmo espaço pode representar para a criança, o espaço-alegria, o espaçomedo, o espaço-proteção, o espaço-mistério, o espaço-descoberta, espaços da liberdade ou da opressão. (Ibidem, p. 65).

Por isso surge uma pergunta importante: quando o espaço torna-se lugar? "O espaço é um conjunto de objetos e ações” (SANTOS, 2011),

(...) mas esse espaço de grande complexidade se torna um lugar quando ele é importante para a realização da nossa vida, quando faz parte do nosso cotidiano e integra a nossa maneira de ser e estar no espaço, a nossa geograficidade (MOREIRA, 2007).

Os momentos que o espaço se torna lugar na educação infantil são diversos, tanto nas ações mais simples e fundamentais da vida - como os momentos das refeições e do descanso, atividades próprias do espaço doméstico - como os espaços lúdicos onde a brincadeira é algo muito sério para a criança no seu processo de significação do mundo. O lugar "que permanecemos a maior parte do tempo enquanto experimentamos a vida” (WINNICOTT, 145, p. 41) é a escola, onde o brincar é a atividade primordial para as crianças nas suas relações com a realidade.

AMBROGI (2011) destaca propostas educativas que sinalizam a importância do espaço escolar para dar vazão à criação e à expressão, próprias da criança. Apresenta Froebel, que institucionaliza as propostas educativas de Rousseau em seu jardim de infância, Freinet nos seus espaços múltiplos, repleto de trocas entre grupos de crianças durante as aulas passeio e Montessori com a proposta da autonomia no espaço para a manipulação dos objetos.

\section{Conclusão}

Os espaços da educação infantil vivenciados no estágio promovem a aprendizagem significativa, dialogam com a realidade das crianças, suas brincadeiras e com as necessidades delas de significar a sua existência no mundo, experimentando texturas, sonoridades, cores e sabores.

Professores, pais, escola e toda comunidade, ao pensar a educação das crianças devem refletir sobre seu espaço, sobre como as crianças vão se apropriar dele, o uso dos objetos, da circulação, das relações que ocorrem nele, dos significados atribuídos para os seus lugares, sua 
dinâmica criativa, suas paisagens, que podem tanto significar acolhimento como medo. É necessário não esterilizar o espaço da educação, considerá-lo apenas como palco pronto, apropriado pelo currículo, mas considerá-lo movimento, construído pelas relações que as crianças estabelecem e o produzem continuamente.

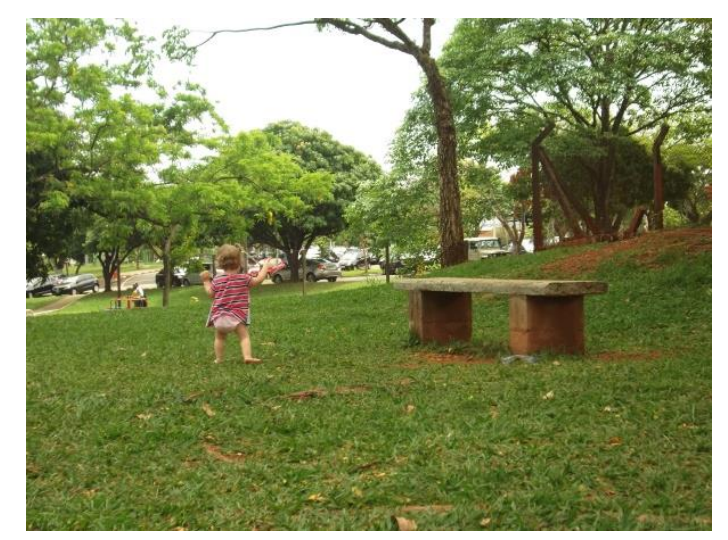

\section{Referências}

AMBROGI, I. H. Reflexões sobre os usos do espaço como garantia para criação de meninos e meninas pequenas. Proposições, Campinas , v. 22, n. 5 (65), p. 63-73, maio/ago. 2011.

MOREIRA, R. Pensar e ser em geografia: ensaios de história, epistemologia e ontologia do espaço geográfico. São Paulo: Contexto, 2007.

SANTOS, M. A natureza do espaço: Técnica e tempo. Razão e emoção. São Paulo: Edusp, 2011.

TUAN, Yu-Fu. Espaço e lugar: a perspectiva da experiência. São Paulo: DIFEL, 1983.

WINNICOTT, D. W. O brincar e a realidade. Rio de Janeiro: Imago editora, 1975.

\section{Sobre a autora}

Ewelyn Mayara Vieira Richieri é graduanda em Pedagogia pela Universidade Estadual de Campinas - UNICAMP, funcionária pública, atua como profissional para assuntos administrativos na seção de Recursos Humanos da Faculdade de Engenharia de Alimentos da UNICAMP.

E-mail: ewelyn.unicamp@gmail.com/ewelyn@unicamp.br. 